\title{
FACTORS ASSOCIATED WITH UNDERNUTRITION OF CHILDREN ADMITTED IN KOSHI ZONAL HOSPITAL NUTRITIONAL REHABILITATION HOME
}

Punam Kumari Mandal*

\begin{abstract}
This study follows mixed method with the objective to assess the factor associated with undernutrition among the children admitted in NRH. This study was conducted in Koshi Zonal Hospital. The study covers the children admitted in NRH and their mothers from $14^{\text {th }}$ March to $28^{\text {th }}$ May 2016 with sample size of 20. The study shows the highest number of children belonged to disadvantaged non Dalit Terai caste groups (35\%) and majorities (45\%) of the mothers found to be illiterate. A statistically significant difference was observed between the mean weight at discharge and the mean weight at admission for the study group $(t=2.98, P<0.008, C I$ 0.46-2.65). The cause of malnutrition was lack of nutritious food, poverty, unhygienic condition at home, diseases and lack of nutritious food during pregnancy. There were knowledge gap regarding the nutrition, causes of malnutrition and its prevention, balanced diet and therapeutic food among the mothers. An urgent need to link these centers with communitybased models was felt necessary to improve health education measures and awareness.
\end{abstract}

Keywords: Undernutrition, factors, children, nutrition rehabilitation home, Koshi Zonal Hospital

\section{INTRODUCTION AND OBJECTIVE}

Good nutrition is a prerequisite for the national development of countries and for the well-being of individuals. Although problems related to poor nutrition affect the entire population, women and children are especially vulnerable because of their unique physiology and socioeconomic characteristics. Adequate nutrition is critical to children's growth and development (NDHS, 2011)

Malnutrition during childhood can lead to a risk of life-style diseases in the future as well as immediate risks of morbidity/mortality.

* Ms. Mandal is an Instructor, Institute of Medicine,Biratnagar Nursing Campus, TU. 
Malnutrition takes a variety of forms. The main types of malnutrition seen in Nepal are protein-energy malnutrition, iodine deficiency disorders, iron deficiency anemia and vitamin A deficiency (National Nutrition Policy \& Strategy, 2004).

Nutritional Rehabilitation Home, Nepal is a specialized facility that rehabilitates severely malnourished children. Nutritional Rehabilitation Home (NRH) was initiated as a project by Olga Murray, the president of Nepal Youth Foundation (NYF) in 1998 A.D. She was motivated to launch this when she visited a malnourished five year old girl in Kanti Hospital, who later died due to negligence of the hospital. It is run by the organizations Friends of Needy Children (FNC) and funded by the Nepal Youth Foundation (NYF). It strives to restore malnourished children to good health and educates their mothers about nutrition and child care. It works with the zonal hospitals in Nepal, nourishing the children that the hospitals refer to the organization. After the rehabilitation homes are firmly established, the Nepal Youth Foundation hands them over to the government after five years of operation. The Center has its headquarters in Lalitpur and the rest of the centers are located throughout the country, in different districts. The objective of this study is to assess the factors associated with undernutrition of Children Admitted in Koshi zonal Hospital Nutrition Rehabilitation Home (NRH).

\section{METHODOLOGY}

A descriptive study with the objective to assess the factor associated with undernutrition among the children admitted in NRH was conducted in Koshi Zonal Hospital NRH. Koshi Zonal Hospital (NRH) was established on 2004 September $1^{\text {st }}$.It provides continuous services to the children. The admission rate is 7-8 children per month. The study population were the children admitted in NRH and their mothers from $14^{\text {th }}$ March to $28^{\text {th }}$ May 2016 with sample size of 20 . Only those children were included in the study who were admitted and were discharged also during data collection period. Quantitative technique included review of individual case files of children. Data review format was developed for data review of anthropometric analysis of nutritional status of child during admission and discharge. Data review also included the data regarding referral by, diagnosis at time of admission and duration of stay. The total duration of data collection was of 10 weeks. For ethical consideration Approval from selected NRH and Koshi Zonal Hospital were taken. The purpose of the study was shared and informed consent was obtained from each respondent. The participant's information was kept confidential and individual dignity was highly respected. Patient's 
medical records werer eviewed retrospectively and all information retrieved from medical records was kept anonymous.Qualitative technique, in-depth interview was carried out using in-depth interview guideline with 20 mothers to explore the mother's knowledge regarding the concept of nutrition, causes and prevention of malnutrition, feeding practices, balanced diet and therapeutic food.

Quantitative Data regarding height, weight, age, sex, length of stay at admission and discharge were collected from NRH register. Collected data were thoroughly checked and edited before data entry. Data entry and analysis was done by using SPSS 16.For quantitative data Descriptive analysis were done by using frequency, mean, median and standard deviation and in inferential analysis Students t test at 95 percent confidence interval was performed to find difference between mean weight of overall group at the time of admission and discharge. For the management of qualitative information, collected data was noted down and later transcribed in detail. Transcripts were then repeatedly read and coded for content. Data analysis was done manually by coding, sorting and summarizing the information into the common themes such as knowledge about NRH, Nutrition, balanced diet, therapeutic feeding and causes and prevention of malnutrition.

\section{RESULTS AND DISCUSSION}

The study group included 20 children of which $14(70 \%)$ were girls and $6(30 \%)$ were boys. About 35 percent (7) of the children were in the age group of more than 49 months and 25 percent (5) in age group of 13-24 months. The median age for the entire group was 36 months. The study showed the highest number of children belonged to Disadvantaged Non Dalit Terai caste groups (35\%), The majority of the children admitted were Hindu (80\%) followed by Muslim $(20 \%)$ and 45 percent of the mothers were illiterate. Regarding the occupation of mothers of children, the study showed that 35 percent of the parents of the admitted children were farmers, 30 percent were house wife, 20 percent were daily wage laborers.

According to mothers information half of the children (50\%) had birth weight less than $2.5 \mathrm{~kg}$. Regarding the immunization status 100 percent children were fully immunized according to EPI programme of government .Regarding feeding practices 90 percent of the mothers had breastfed their children. Regarding the knowledge of colostrums feeding 60 percent said that it is good practice. In majority of the children $(70 \%)$ there is no weaning practice at all whereas in 20 percent of children the weaning age was 6 months and 10 percent of the children it was 1 year. When the mothers were asked about the time of complementary feeding 
introduced majority of the mother (65\%) said 7 months to 1 year.This study revealed that almost all (100\%) mothers had access of water supply to their home. Sources of drinking water in majority of the mothers (95\%) were tube well. Regarding the distance to water source majority of mother (95 $\%$ ) said less than 10 minute. About the type of toilet used 50\% mothers said they use pakka toilet, kachchi in 15 percent and 35 percent mothers don't have toilet in their home, they practice open field defecation. Almost all mothers $(100 \%)$ had health facility at their home area .the distance to health facility is less than $5 \mathrm{KM}$ in 55 percent of the mothers and more than $5 \mathrm{KM}$ in 45 percent of the mothers.

A statistically significant difference was observed between the mean weight at discharge and the mean weight at admission for the study group ( $(\mathrm{t}=2.98, \mathrm{P}<0.008, \mathrm{CI} 0.46-2.65))$. The cause of malnutrition was lack of nutritious food, Poverty, poor sanitation at home, diseases and lack of nutritious food during pregnancy. Most mothers believed that NRH program was very effective as it was helping many severely malnourished children to recover and return home healthy. In addition to in-depth interviews conducted with 20 mothers of children who were admitted in NRH and observations were made. The mothers were asked questions regarding the knowledge about $\mathrm{NRH}$, their experiences at $\mathrm{NRH}$, things they learnt there, knowledge regarding nutrition, balanced diet, therapeutic food and causes of malnutrition. Most of the mothers said that nutrition is to provide balance diet in adequate amount and it is very important to maintain health of their child .According to most of the mothers, the cause of malnutrition was lack of nutritious food to child. Poverty was stated as ultimate reason for insufficiency of food. They explained, because they were poor, they could not provide nutritious and balanced diet as was provided at NRH. Some of them even expressed not knowing how to feed the children, unhygienic condition at home and diseases as reason for malnutrition. Some of the emphasized that lack of nutritious diet during pregnancy is also the leading cause of malnutrition. Seven mothers even didn't know about the causes of malnutrition. According to most of the mothers the causes of malnutrition in their children are inadequate eating, lack of sanitation and nutritional deficiency during pregnancy

Regarding the prevention of malnutrition most of the mother said that taking nutritious diet timely helps to prevent from malnutrition. Some of them stated that green vegetables and sanitation also necessary to prevent malnutrition . Regarding learning about nutrition at NRH most of the mother stated that they learned to prepare lito, jaulo, balanced diet 
and also learned how to maintain sanitation. In this context, a mother of an admitted children in Nutrition Rehabilitation. Home, Zonal Hospital during study period said: "I think during pregnancy I had not eaten nutritious food properly and I gave birth to low birth weight child. Now that child becomes malnourished".

When asked about feeding practices majority of mothers said they did not weaned their children and the age of introduction of complementary feeding in most mothers were 7 months to 1 year age of children. In composition of complementary feeding majority of the mother includes rice, dal, vegetable which is locally available in their home where as some of mothers included jaulo, lito, Cow's milk and cerelec. Few of them included fruits, sarbottampitho etc. Regarding sanitation majority of mothers had understanding about the sanitation and they used to wash hand before and after introduction of food to their children and informed about it at NRH. They said it is very important to maintain health and development of the children. When asked about understanding of balanced diet most of the mother said that it is the mixture of all kind of food and it is very necessary to maintain health and growth and development of the child. They informed about preparation of balanced diet and they used to prepare it in their home using locally available resources whereas among them nine mothers don't know about balanced diet and preparation. Regarding therapeutic food most of the mothers don't know about it, and method of preparation .some of the mothers said that it is given at the time of treatment and is needed during the course of illness when the child is suffered from malnutrition.

In response to the question regarding their nutritional practices at home, most of the mothers said that they will practice all that they had learnt at NRH. Before the admission to NRH it was not possible to prepare food for child separately. According to them, the children were fed with the food that was prepared for other family members. But most of them acknowledged that they have been maintaining hygiene, washing hands before feeding, washing the vegetables before cutting, covering the food.Now they informed about the importance of nutrition and method of preparing balanced diet using locally available resources andable to practice it at home. 


\section{FACTORS ASSOCIATED WITH UNDERNUTRITION OF ...}

Table1: Mean Weight at Admission and Discharge $(n=20)$

\begin{tabular}{|l|c|c|c|}
\hline \multicolumn{1}{|c|}{ Age group } & $\begin{array}{c}\text { Mean wt. }(\mathrm{kg}) \\
\text { admission }\end{array}$ & $\begin{array}{c}\text { Mean wt. }(\mathrm{kg}) \\
\text { Discharge }\end{array}$ & p-value/CI \\
\hline$<12$ months $(\mathrm{n}=4)$ & $3.45( \pm 1.06)$ & $4.71( \pm 2.29)$ & \\
\hline $13-36$ months $(\mathrm{n}=8)$ & $7.50( \pm 1.66)$ & $8.93( \pm 2.38)$ & \\
\hline$>36$ months $(\mathrm{n}=8)$ & $14.1( \pm 5.66)$ & $16.06( \pm 4.90)$ & \\
\hline Overall average $(\mathrm{n}=20)$ & $9.33( \pm 5.59)$ & $10.89( \pm 5.75)$ & $\mathrm{p}<0.008$, CI $0.46-2.65$ \\
\hline
\end{tabular}

Source: Field survey, 2016

Table 2: Comparison Between Height of Children at Admission and Discharge $(n=20)$

\begin{tabular}{|c|c|c|c|c|}
\hline $\begin{array}{c}\text { Age } \\
\text { (in Months) }\end{array}$ & $\begin{array}{c}\text { Mean Height } \\
\text { at admission } \\
(\mathrm{cm})\end{array}$ & $\begin{array}{c}\text { Mean Height } \\
\text { at discharge } \\
(\mathrm{cm})\end{array}$ & $\begin{array}{c}\text { No change } \\
\text { in Height } \\
(\mathrm{cm})\end{array}$ & $\begin{array}{c}\text { Change } \\
\text { in Height } \\
(\mathrm{cm})\end{array}$ \\
\hline$<12$ months $(\mathrm{n}=4)$ & 55 & 55 & $4(20 \%)$ & $0(00 \%)$ \\
\hline $13-36$ months $(\mathrm{n}=8)$ & 75.5 & 77.75 & $6(30 \%)$ & $2(10 \%)$ \\
\hline$>37$ months $(\mathrm{n}=8)$ & 115.37 & 117.87 & $5(25 \%)$ & $3(15 \%)$ \\
\hline Total $(\mathrm{n}=20)$ & 87.35 & 89.25 & $15(75 \%)$ & $5(25 \%)$ \\
\hline
\end{tabular}

Source: Field survey, 2016

Table 3: Nutrition Status of the Children at the Time of Admission and Discharge $(n=20)$

\begin{tabular}{|l|c|c|}
\hline & Mild or moderate malnutrition & Severe malnutrition \\
\hline Admission & $11(55 \%)$ & $9(45 \%)$ \\
\hline Discharge & $15(75 \%)$ & $5(25 \%)$ \\
\hline
\end{tabular}

Source: Field survey, 2016

The study findings show that a major proportion of the admitted children belonged to the marginalized population groups. The findings are in accordance with the findings of the study done in selected NRCs of Madhya Pradesh. The majority of children (70\%) were female, about 35 percent of the children were in the age group of more than 49 months. This study showed that 35 percent of the parents of the admitted children were farmers, 30 percent were house wife similar finding were reported in a study conducted in Malawi More than 60 percent of the caregivers had never attended school. Of those who had attended school the majority had completed primary school (Savado and Dramaix inetal. 2007). In this study according to mother's information the half of the children $(50 \%)$ 
had birth weight less than $2.5 \mathrm{~kg}$.More specifically for Nepal, one of the important causes of the high malnutrition rates is that some 30-50 per cent of children are born with a low birth weight. The high prevalence of low birth weight means that many Nepali children are already seriously affected by malnutrition when they are born. Low birth weight also leads to an intergenerational cycle of malnutrition. Small baby girls become small mothers, giving birthto small babies (UNICEF, 2006). Weight has been taken as the main anthropometric measure as an improvement of severe malnourished children. The study findings reveals a statistically significant difference between the mean weight at discharge and the mean weight at admission for the entire study group $(\mathrm{t}=2.65, \mathrm{P}<0.008)$. similarly study conducted by Colecraft and Maetz et al., 2004) at four day care NRCs also reported a significant increase in weight for age for the admitted children. Another study conducted by Taneja et al., 2012) had showed a statistically significant difference between the mean weight at discharge and the mean weight at admission for the entire study group $(\mathrm{t}=25.243, \mathrm{P}<0.001)$ for boys $(\mathrm{t}=21.673, \mathrm{P}<0.001)$ and girls $(\mathrm{t}=15.044, \mathrm{P}<0.001)$.

In this study according to most of the mothers, the cause of malnutrition was lack of nutritious food to child. Poverty was stated as ultimate reason for insufficiency of food. Some of them even expressed not knowing how to feed the children, unhygienic condition at home and diseases as reason for malnutrition. Some of the emphasized that lack of nutritious diet during pregnancy is also the leading cause of malnutrition. Seven mothers even did't know about the causes of malnutrition. A study conducted on Malawi regarding the contributing factors of under nutrition among the children admitted in Nutritional rehabilitation unit with sample size 70 showed that lack of resources of different kinds seemed to be a limiting factor for the caregivers to provide adequate care to the children. These resources were related to support, time, knowledge, a healthy environment and access to medical assistance (Stalcrantz \& Holmboe, 2006)

\section{CONCLUSION}

The Nutritional Rehabilitation Home were found to be effective in improving the condition of admitted children as statistically significant difference was observed between the mean weight at discharge and the mean weight at admission for the study group. The causes of malnutrition were lack of nutritious food to child, Poverty, unhygienic condition at home and diseases, lack of nutritious food during pregnancy as the reason for malnutrition. The mothers were satisfied with the rehabilitation of 
their children. They believed that NRH program was very effective as it was helping many severely malnourished children to recover and return home healthy. The study showed that there is knowledge gap regarding the nutrition, causes of malnutrition, its prevention, balanced diet and therapeutic food among the mothers.

\section{ACKNOWLEDGEMENTS}

I would like to express my sincere gratitude to the Centre for Research, Rector's office, TU for proving grants to conduct this research. I am very grateful to Biratnagar Nursing Campus, Koshi Zonal Hospital and all the respondents for their valuable information and cooperation.

\section{REFERENCES}

Colecraft E. K., Marquis G. S., Bartolucci A. A., Pulley L., Owusu W. B., \& Maetz H. M. (2004). A longitudinal assessment of the diet and growth of malnourished children participating in nutrition rehabilitation centres in Accra, Ghana. Public Health Nutr; 7:48794.

National Nutrition Policy and Strategy, (2004). Kathmandu: Nutrition Section, Child Health Division, Ministry of Health and Population.

Savadogo L., Zoetaba I., Donnen P., Hennart P., Sondo B. K., \& Dramaix M. (2007). Management of severe acute malnutrition in an urban nutritional rehabilitation center in Burkina Faso. Rev Epidemiol Sante Publique., 55:265-74.

Taneja G. S., Dixit S., et al. (2012). A study to evaluate the effect of nutritional intervention measures on admitted children in selected nutrition rehabilitation centers of indore and ujjain divisions of the state of madhyapradesh India, Indian J Community Med 37(2): 107-115.

UNICEF(2006). Situation of children and women in Nepal. Kathmandu: Author. 